\title{
A BIOÉTICA LATINO-AMERICANA: HISTORICIDADE, ATUALIDADE E OPERACIONALIZAÇÃO DO CONCEITO
}

\author{
LATIN AMERICAN BIOETHICS: HISTORICITY, PRESENT AND \\ OPERATIONALIZATION OF THE CONCEPT
}

Pablo Jiménez Serrano

Doutor em Direito pela Faculdade de Direito da Universidade do Oriente, Cuba. Professor e pesquisador do Programa de Mestrado em Direito do Centro Universitário Salesiano de São Paulo- UNISAL. Professor e pesquisador do Centro Universitário de Volta Redonda UniFOA. Professor e pesquisador do Centro Universitário de Barra Mansa - UBM. E-mail: contato@jurismestre.com.br

Lino Rampazzo

Doutor em Teologia pela Pontificia Università Lateranense (Roma) Pós-doutor em Democracia e Direitos Humanos pela Universidade de Coimbra/Ius Gentium Conimbrigae. Professor e Pesquisador no Programa de Mestrado em Direito do Centro Unisal - U.E. de Lorena (SP). E-mail: lino.rampazzo@uol.com.br

Recebido em: 27/10/2016

Aprovado em: 03/05/2017

Doi: $10.5585 / \mathrm{rdb} . v 17 \mathrm{i} 7.521$

RESUMO: No presente ensaio objetiva-se desenvolver uma reflexão acerca da evolução e da correlação dos conceitos ética, bioética e biodireito de forma de avaliar a atualidade e operacionalização dos termos, em face da melhor resolução dos dilemas que enfrenta a sociedade brasileira e, por extensão, a latino-americana. Por meio dos métodos bibliográfico, histórico, documental e comparado, desenvolve-se uma análise conceitual e epistemológica, procura-se, assim, discutir os significados atribuídos aos construtos em estudo e destacar a utilidade e a função da Bioética como microssistema. Discute-se, igualmente, o caráter multidisciplinar e complexo de uma nova Bioética para o atual contexto sociocultural que se sabe sujeito às constantes mudanças oriundas dos problemas nacionais e globais hodiernos. Investigam-se os princípios que definem a bioética latino-americana e conclui-se que o respeito, a solidariedade, responsabilidade e a cooperação são, dentre outros, aqueles que devem ser promovidos para uma melhor operacionalização dos conceitos em estudo.

Palavras-chave: Ética. Bioética. Biodireito. América Latina.

ABSTRACT: The present study intends to develope a reflection about evolution and the correlation between the concepts Ethics, Bioethics and Biolaw in order to evaluate the actuality and operationalization of these terms in view of the best resolution of the dilemmas that the Brazilian society faces, and by extension, also the Latin American one. It intends therefore to discuss the meanings attributed to the constructs under study and highlight the usefulness and function of Bioethics as a microsystem. It is likewise discussed the multidisciplinary and complex character of a new Bioethics for the current sociocultural context, that is known by 
being subject to the constant changes deriving from national and global modern-day problems. The principles that define Latin American Bioethics are investigated and it is concluded that respect, solidarity, responsability and cooperation are, among others, those which must be promoted to a better operationalization of the concepts under study.

Keywords: Ethics. Bioethics. Biolaw. Latin America.

SUMÁRIO: Introdução. 1 Origem e historicidade da Bioética. 1.1 Campo de estudo da Bioética. 1.2 Engenharia Genética, questão ecológica e bioética. 1.3 Os princípios bioéticos. 2 Atualidade da Bioética. 2.1 Microética e macroética. 3 Operacionalização do conceito Bioética. Conclusão. Referências.

\section{INTRODUÇÃO}

Os conceitos modernos de Bioética e de Biodireito estão imersos numa nova realidade global que se sabe cada vez mais diferente e distante daquela realidade que lhes deu origem no alvorecer dos anos 1970.

Certamente, na sua primeira década de existência, a Bioética foi considerada basicamente um "movimento dos Estados Unidos" (GARCIA, 2007, p. 17) nascido da preocupação com o uso inadequado das tecnologias e com os próprios resultados das pesquisas científicas. Mas, com o passar do tempo foi adotada (e adaptada) por outros países, fundamentalmente, nos países da América Latina (MAINETTI, 2007, p. 35), onde, também, as tecnologias poderiam ser colocadas em conflito com a Vida, pois os resultados das pesquisas poderiam ser transformados em novas formas de mercadorias, fetiches ou meros desejos de consumo.

Modernamente, entretanto, os problemas bioéticos consideram-se maiormente vinculados aos direitos humanos e fundamentais, pois as diversas práticas nesta área colocam em crise o reconhecimento e a afirmação do direito à Vida, a dignidade, a convivência etc., ou conflitam com os princípios e valores inatingíveis, que se sabem verdadeiras conquistas das sociedades modernas, fundamentalmente, dos países latino-americanos.

A evolução constante dos direitos humanos e fundamentais e o alargamento das suas dimensões trouxeram novos dilemas éticos que também são oriundos da velocidade surpreendente do progresso nesse campo, motivo pelo qual tornou-se necessário à UNESCO elaborar um sistema voltado para a elaboração e implementação de importantes declarações, tais como a Declaração Universal sobre Bioética e Direitos Humanos e, igualmente, a Conferência Geral da UNESCO que, em sua $30^{\circ}$ sessão (1999), adotou as "Diretrizes para a Implementação da Declaração Universal sobre o Genoma Humano e os Direitos Humanos”, elaboradas pelo Comité Internacional de Bioética e aprovadas pelo Comitê Intergovernamental de Bioética. Tornou-se evidente que os temas bioéticos têm uma estreita ligação com princípios universais dos direitos humanos, particularmente aqueles estabelecidos na Declaração Universal dos Direitos Humanos de 10 de dezembro de 1948 e nos dois Pactos Internacionais das Nações Unidas, respectivamente, sobre Direitos Econômicos, Sociais e Culturais e sobre Direitos Civis e Políticos de 16 de dezembro de 1966, assim como outras convenções e declarações das Nações Unidas. Afirma-se, contudo, que tais declarações e convenções precisam ser implementadas com especial urgência, em função da velocidade sempre crescente do progresso técnico e científico da biologia e da genética pois, mesmo que cada avanço quase infalivelmente traz novas esperanças para a melhoria do bem-estar da humanidade, também gera dilemas éticos sem precedentes.

No entanto, considera-se discutível o caráter (vinculante) desses documentos que, obviamente, precisam serem implementados pelos Estados. Importa saber até que ponto eles podem ser considerados obrigatórios ou se, pelo contrário, significam um mero apelo à 
observação dos deveres dos Estados, motivo pelo qual colocam-se em crise os conceitos tradicionais em estudo: ética, bioética e biodireito.

Surge, assim, a necessidade de se repensarem as significações historicamente atribuídas a esses construtos com o objetivo de ser reconstruído o projeto teórico, metodológico que nos permita, de forma coerente, tornar operacional o sistema internacional vigorante em matéria de Bioética, de modo a concretizar os direitos, princípios e diretrizes contidas naqueles documentos.

Do ponto de vista metodológico, no presente texto investiga-se a atualidade dos conceitos em estudo. Assim, por meio dos métodos bibliográfico, histórico, documental e comparado desenvolve-se uma abordagem conceitual e epistemológica, procurando-se, assim, discutir os significados atribuídos aos construtos em estudo e destacar a utilidade e a função da Bioética como microssistema. Discute-se, igualmente, o caráter multidisciplinar e complexo de uma nova Bioética para o atual contexto sociocultural que se sabe sujeito às constantes mudanças oriundas dos problemas nacionais e globais hodiernos.

Privilegia-se, igualmente, uma investigação dos princípios que definem a bioética latinoamericana e conclui-se que o respeito, a solidariedade, responsabilidade e a cooperação são, dentre outros, aqueles que devem ser promovidos para uma melhor operacionalização dos conceitos em estudo.

Do ponto de vista normativo, pode-se dizer, o mundo está tecnicamente bem equipado, pois conta-se com uma diversidade de legislações transnacionais e nacionais sobre Bioética. Porém, na sua dimensão prática, cada vez mais os conceitos se desatualizam por causa da diversidade de decisões em conflito que parecem apontar para a ausência de uma "identidade" biomoral. Vê-se como alguns problemas, tais como o aborto, a eutanásia, as penas de morte, dentre outros, são abordados de forma diferentes e divergente nos diferentes país da região.

É possível, com efeito, afirmar que contamos com uma pluralidade ideológica, institucional e metodológica que faz com que cada país, sociedade, grupo humano ou indivíduo pense, ainda, a Bioética e o Biodireito com base nas exortações e princípios propostos pelos eticistas e bioeticistas anglo-saxões por meio dos quais torna-se predominante a defesa de uma moral balizada pela "autonomia" (as liberdades) princípio muitas vezes visto como inapropriado para a resolução de todos os problemas biomorais comunitários e nacionais.

O maior problema da Bioética latino-americana e mundial é a diversidade de formas de se pensar os conceitos em estudo nas diferentes realidades nacionais. Certamente, é essa diversidade a que estimula a presente investigação em face da procura por uma "unidade conceitual" que possibilite a adequada resolução do problema trazido pela diversidade e em face da identidade (conjunto de caracteres que são comuns ao ser humano).

Neste sentido, acredita-se que a Bioética no contexto latino-americano e mundial, tem como função ratificar a necessidade do retorno aos "valores comuns" que constituem a nossa identidade e que irão garantir a nossa convivência. É, por esse motivo, que, a seguir, discutem-se as razões da atualização dos conceitos em função concretização das diretrizes emanadas da Declaração Universal sobre Bioética e Direitos Humanos e da Declaração Universal sobre o Genoma Humano e os Direitos Humanos.

\section{ORIGEM E HISTORICIDADE DA BIOÉTICA}

Desde 1971, quando apareceu o vocábulo "bioética" no artigo escrito pelo oncólogo Van Rensselaer Potter, da Universidade de Wisconsin (E.U.A.), com o título The science of survival, e no ano seguinte, no volume do mesmo autor com o título Bioethics: bridge to the future, esse nome teve um rápido e grande sucesso.

$\mathrm{Na}$ realidade o termo tinha aparecido em 1927 no editorial do periódico de ciências naturais Kosmos, intitulado Bioética: um panorama da ética e as relações do ser humano com os animais e plantas. Autor do editorial foi Fritz Jahr, pastor protestante. 
A despeito do título sugerir uma formulação da Bioética direcionada mais ao meio ambiente, Jahr pretendia dizer que, se devia ser respeitada toda a forma de vida, inclusive animais e plantas, tanto mais deviam ser respeitados os humanos (no caso, os judeus). Para ponderar corretamente o contexto no qual deve ser compreendida a formulação de Bioética feita por Fritz Jahr, é importante lembrar que surgiu na mesma época e no mesmo país onde o nazismo estava estruturando sua linha de pensamento (HOSS, 2013).

Voltando para Potter, com quem o termo ganhou muita notoriedade, a origem da palavra bioética está ligada ao diagnóstico dramático que ele apresentou. Nos seus escritos apontou para o perigo que representa para a sobrevivência de todo o ecossistema a separação entre duas áreas do saber, o saber científico e o saber humanista.

A clara distinção entre os valores éticos, que fazem parte da cultura humanista em sentido lato, e os fatos biológicos está na raiz daquele processo científico-tecnológico indiscriminado que, segundo Potter, põe em perigo a própria humanidade e a própria sobrevivência sobre a terra. O único caminho possível de solução para essa iminente catástrofe é a constituição de uma ponte entre as duas culturas: a científica e a humanístico-moral. Em outros termos, a ética não deve se referir somente ao homem, mas deve estender o olhar para a biosfera em seu conjunto, ou melhor, para cada intervenção científica do homem sobre a vida em geral. A bioética, portanto, deve se ocupar de unir a "ética" e a "biologia", os valores éticos e os fatos biológicos para a sobrevivência do ecossistema como um todo. O "instinto" de sobrevivência não basta: é preciso elaborar uma "ciência" da sobrevivência que o autor identifica com a bioética.

Trata-se de superar a tendência pragmática do mundo moderno, que aplica imediatamente o saber sem uma mediação racional e, muito menos, moral: a aplicação de todo conhecimento científico pode ter, de fato, consequências imprevisíveis sobre a humanidade, até por efeito da concentração do poder biotecnológico nas mãos de poucos.

Na concepção de Potter, portanto, a bioética se movimenta a partir de uma situação de alarme e de uma preocupação crítica a respeito do progresso da ciência e da sociedade.

Outra característica do pensamento bioético é que essa nova reflexão deve se ocupar, ao mesmo tempo, de todas as intervenções na biosfera e não apenas das intervenções sobre o homem. Há, portanto, uma concepção mais ampla em relação à ética médica tradicional.

\subsection{Campo de estudo da Bioética}

Em 1978, a Encyclopedia of Bioethic fala sobre a "bioética" nos seguintes termos: "Bioética é um neologismo derivado das palavras gregas bios (vida) e ethike (ética). Pode-se defini-la como sendo o estudo sistemático da conduta humana no âmbito das ciências da vida e da saúde, utilizando uma variedade de metodologias éticas num contexto interdisciplinar".

O âmbito das ciências da vida e da saúde compreende, por isso, a consideração da biosfera, para além da medicina; as intervenções podem ser as que se referem às profissões médicas, mas também as das populações, p. ex. as que se referem aos problemas demográficos e ambientais; a especificidade desse estudo sistemático define-se pela referência a valores e princípios éticos e, por isso, à definição de critérios, juízos e limites de licitude ou de ilicitude.

Enquanto ética aplicada ao 'reino biológico', que designa um universo muito mais amplo do que o da medicina, a bioética abrange a ética médica tradicional e se amplia incluindo: a) os problemas éticos de todas as profissões sanitárias; b) os problemas sociais unidos às políticas sanitárias, à medicina do trabalho, à saúde internacional e às políticas de controle demográfico; c) os problemas da vida animal e vegetal em relação à vida do homem.

Os instrumentos de estudo da bioética resultam da metodologia interdisciplinar específica que se propõe examinar de modo aprofundado e atualizado a natureza do fato biomédico (momento epistemológico), ressaltar suas implicações num plano antropológico 
(momento antropológico) e identificar as 'soluções' éticas e as justificativas de ordem racional que sustentam essas soluções (momento aplicativo).

A reflexão sobre a bioética tem hoje configurados três diferentes momentos: a bioética geral, a bioética especial e a bioética clínica.

A bioética geral, que se ocupa das fundações éticas, é o discurso sobre os valores e sobre os princípios originários.

A bioética especial, que analisa os grandes problemas, enfrentados sempre sob o perfil geral, tanto no terreno médico, quanto no terreno biológico: saúde pública, fertilidade, engenharia genética, aborto, doação e transplante de órgãos, eutanásia, experimentação clínica, meio ambiente etc.

\subsection{Engenharia Genética, questão ecológica e bioética}

A Bioética, em suma, é uma disciplina relativamente nova que trata de problemas éticos relacionados à vida humana, principalmente a descobertas recentes na medicina, Biologia $\mathrm{e}$ Engenharia Genética, o que tem trazido alterações profundas nos padrões habituais que, em muitos casos, simplesmente não previam situações hoje possíveis do ponto de vista científico, porém no mínimo problemáticas do ponto de vista ético. Alguns exemplos mais contundentes são os casos, tornados possíveis pela inseminação artificial, de "barrigas de aluguel". Até que ponto é ético uma mulher alugar seu útero? Quem é finalmente a mãe em um caso como este? Que implicações isto poderá ter para a criança no futuro? Estas são algumas das questões que, em grande parte, permanecem em aberto e têm sido muito discutidas. A clonagem, a possibilidade de reprodução da vida por meio de avanços tecnológicos na Genética suscita também perplexidades com as quais estamos apenas começando a lidar.

Quanto à questão ecológica, há uma revisão de nossos parâmetros habituais de relação com o meio ambiente, envolvendo uma série de questões éticas. Desde o início do período moderno (séc. XVI), e principalmente após a Revolução Industrial (séc. XIX), nossa cultura ocidental tem vivido a ideologia do progresso, segundo a qual podemos e devemos explorar a natureza, extraindo desta a matéria-prima para seu desenvolvimento técnico e industrial. Só muito recentemente o ser humano tem despertado para os riscos e consequências desastrosas dessa atividade. Problemas como poluição, destruição de ecossistemas provocando a extinção de espécies animais e vegetais, esgotamento de recursos etc., nos revelam que em nome do aparente "bem-estar" de uma geração podemos estar entregando às gerações futuras um mundo devastado e um meio ambiente até mesmo inabitável. Novas responsabilidades surgem, portanto, na medida em que adquirimos uma maior consciência da importância do meio ambiente. Não só devemos reconhecer o mundo em que habitamos como uma realidade viva com a qual devemos nos relacionar eticamente, como também devemos reconhecer que de um ponto de vista ético temos uma grande responsabilidade com o futuro da nossa e das demais espécies que habitam este mundo, e que esta responsabilidade deve orientar nosso relacionamento com a natureza.

\subsection{Os princípios bioéticos}

Responder aos problemas apresentados pelo progresso científico significa repropor a pergunta sobre o valor da pessoa, sobre suas prerrogativas e sobre seus deveres.

O valor fundamental da vida, o valor transcendente da pessoa, a concepção integral da pessoa (síntese unitária de valores físicos, psicológicos e espirituais), a relação entre pessoa e sociedade são pontos de referência para a bioética. Estes valores deverão ser confrontados e compostos com os problemas emergentes do desenvolvimento da ciência biomédica, que, apesar do entusiasmo provocado pelas suas recentes descobertas, não pode esquecer-se dos desafios das 
doenças não dominadas, da prevenção dos males provocados pela própria sociedade tecnológica e gerados pela exploração ecológica. bioética.

Com estas premissas, pode-se enunciar e explicar alguns princípios e orientações da

\section{a) A defesa da vida física}

A vida corpórea não exaure toda a riqueza da pessoa que é também, e antes de mais nada, espírito e, por isso, como tal, transcende o próprio corpo e a temporalidade. Todavia, com relação à pessoa, o corpo é co-essencial, é sua encarnação primeira, o fundamento por meio do qual a pessoa se realiza, se expressa e se manifesta.

É emergente, portanto, a importância desse princípio em ordem à manifestação dos vários tipos de supressão da vida humana: homicídio, suicídio, aborto, eutanásia, genocídio, guerra de conquista e assim por diante. Não é possível aceitar, de um ponto de vista ético, a hipótese da supressão direta e deliberada da vida de alguém para favorecer a vida de outros ou as melhores condições político-sociais de outros.

No âmbito da promoção da vida humana está inserido o tema da defesa da saúde do homem. O assim chamado "direito à saúde" aponta para a obrigação ética de defender a promover a saúde para todos os seres humanos e à proporção de sua necessidade. A este respeito pronunciou-se, já em 1948, a Constituição da Organização Mundial da Saúde, no seu art. 25.

\section{b) Liberdade e responsabilidade}

Partindo do princípio pelo qual a liberdade-responsabilidade constitui a fonte do ato ético, podem-se considerar alguns reflexos no campo da bioética.

Assim, a liberdade-responsabilidade do médico não pode transformar o tratamento em coação, quando a vida não está em questão. É o problema do consentimento do paciente. Há um consentimento implícito desde o momento em que o paciente se põe nas mãos do médico para que faça tudo o que for necessário para o tratamento e a recuperação da saúde. Este consentimento, todavia, não dispensa o médico do dever de informar o paciente sobre o andamento da terapia e de pedir ulterior e explícito consentimento todas as vezes que houver circunstâncias não previstas: um tratamento que comporte risco, ou a experimentação de um remédio. É preciso ter sempre presente que a vida e a saúde são confiadas prioritariamente à responsabilidade do paciente e que o médico não tem sobre o paciente outros direitos superiores aos que o próprio paciente tem a respeito de si mesmo.

\section{c) Princípio de totalidade ou princípio terapêutico}

É este um dos princípios basilares e característicos da ética médica. Fundamenta-se ele no fato de que a corporeidade humana é um todo unitário resultante de partes distintas e unificadas orgânica e hierarquicamente entre si pela existência única e pessoal.

O princípio da inviolabilidade da vida, que é primeiro e fundamental, não é negado, mas, ao contrário, posto em prática toda vez que, para salvar o todo, e a própria vida do sujeito, é preciso intervir de maneira mutilante sobre uma parte do organismo. Fundamentalmente, esse princípio regula toda a licitude e a obrigatoriedade da terapia médica e cirúrgica. É por isso que o princípio se chama também princípio terapêutico.

O princípio terapêutico tem aplicações particulares não somente nos casos gerais da intervenção cirúrgica, mas também em casos mais específicos, como a esterilização terapêutica ou o transplante de órgão. Além disso, este princípio tem sua aplicação na norma da "proporcionalidade das terapias". De fato, ao se pôr em prática uma terapia, esta deve ser avaliada dentro da totalidade da pessoa: por isso precisa haver uma certa proporção entre os riscos e danos que ela comporta e os benefícios que ela traz. Pôr em prática tratamentos desproporcionais, ou para enganar o paciente, dando a impressão da eficiência, ou para satisfazer 
o pedido do paciente ou dos parentes de "fazer de tudo" sem resultados previsíveis, pode significar uma atitude de agressividade ou de insistência terapêutica.

\section{d) Socialidade e subsidiaridade}

A pessoa é essencialmente aberta à sociedade e a socialidade é uma característica intrínseca da personalidade. A própria situação de fato comprova que a vida e a saúde de cada um dependem também do apoio dos outros.

Assim, o princípio da socialidade obriga cada pessoa a se realizar na participação da realização do bem dos próprios semelhantes. No caso da promoção da vida e da saúde, isso importa em que cada cidadão se obrigue a considerar a própria vida e a do outro como um bem não apenas pessoal, mas também social, e obriga a comunidade a promover a vida e a saúde de cada um, a promover o bem comum pela promoção do bem de cada um.

Para nos darmos conta da importância desse princípio ético, basta considerar a situação da saúde no caso de poluição e de epidemias contagiosas, basta observar o conjunto de serviços que constituem a assistência médica, em que a recuperação da saúde se torna possível à medida que existe múltipla colaboração de profissões, de competências e de intervenções legislativas.

O princípio de socialidade pode chegar até a justificar a doação de órgãos e tecidos, que, embora comporte certa mutilação do doador, pode estimular o voluntariado assistencial e, como aconteceu em quase todo o mundo, fazer surgir obras assistenciais (hospitais, centros de saúde) somente pelo sentimento de serviço fraterno dos sãos para com os doentes.

Mas, em termos de justiça social, o princípio obriga a comunidade a garantir a todos os meios de acesso aos tratamentos necessários, ainda que seja a custo de sacrifícios dos que estão bem.

E é neste momento que o princípio de socialidade se une ao de subsidiaridade, pelo qual a comunidade deve, de uma parte, ajudar mais onde mais grave é a necessidade (ter mais cuidados com quem mais necessita de cuidados e gastar mais com quem está mais doente) e, de outra, não deve suplantar ou substituir iniciativas livres de cada um e dos grupos, mas garantir seu funcionamento (SGRECCIA, 2002).

\section{e) Os princípios de autonomia, benefício e justiça}

$\mathrm{Na}$ literatura específica sobre bioética, sobretudo na inglesa, encontra-se a referência a outros princípios fundamentais que deveriam guiar o médico na sua relação com o paciente e em geral em toda ação ou escolha no campo biomédico. Beauchamps e Childress (2001) elaboraram uma espécie de "paradigma" ético voltado para quem trabalha na área da saúde, com o fim de fornecer uma referência prático-conceitual que os pudesse orientar nas situações concretas. Esse "paradigma" é constituído pela formulação dos princípios de autonomia, benefício e justiça.

O princípio de autonomia refere-se ao respeito devido aos direitos fundamentais do homem, inclusive o da autodeterminação. Esse princípio se inspira na máxima "não faças aos outros aquilo que não queres que te façam" e está, portanto, na base de uma moralidade inspirada no respeito mútuo. É sobre esse princípio que se fundamentam sobretudo a aliança terapêutica entre médico e paciente e o consentimento aos tratamentos diagnósticos e de terapias.

O princípio de benefício não comporta somente o abster-se de prejudicar, mas implica sobretudo o imperativo de fazer ativamente o bem e até de prevenir o mal.

O princípio de justiça se refere à obrigação de igualdade de tratamento e, em relação ao Estado, de justa distribuição das verbas para a saúde, para a pesquisa etc.

Este princípio foi gestado ao longo dos três últimos séculos como parte da consciência da cidadania e luta pelo direito à saúde, até chegar a ser um direito de todos.

O citado bioeticista italiano Elio Sgreccia faz referência a esta terminologia utilizada sobre a bioética, principalmente na literatura inglesa, na qual se apresentam os princípios de benefício, de autonomia e de justiça. Ele afirma que: 
indubitavelmente há elementos de validade nesses três princípios e, se observamos bem, poderia haver neles uma correspondência com o princípio terapêutico, o princípio de liberdade e responsabilidade, o princípio de subsidiaridade...Mas se aqueles nos parecem coerentemente unidos entre si por uma antropologia personalista que os fundamenta, que definitivamente faz referência a um bem integral da pessoa,...não ocorre o mesmo com estes (2002, p. 166-167).

Ele, logo em seguida, procura explicar que muitas vezes os princípios de benefício, autonomia e justiça são tomados como absolutos, sem que se esclareça o que deve ser entendido como bem da pessoa, ou autonomia do indivíduo. Faz o exemplo da relação entre médico, paciente e sociedade que não pode ficar numa dimensão apenas horizontal, mas deve ser posta "fora deles, deve transcendê-los" (2002, p. 167).

A crítica de Sgreccia merece um profundo debate, que não pode ser desenvolvido na brevidade deste artigo. Aponta-se, porém, de maneira particular, para uma indevida aplicação do princípio de "autonomia" que poderia ser aplicado num uso indiscriminado da tecnologia, considerada quase como um "absoluto" que passa por cima dos direitos das pessoas. Esta reflexão será retomada na conclusão deste estudo.

Uma outra consideração diz respeito ao lugar onde nasceu a bioética, a saber, dentro do próprio contexto de evolução dos países de Primeiro Mundo: ela é fruto de uma sociedade que atingiu a democracia - com pleno exercício da cidadania, com a afirmação do sujeito instruído de uma sociedade pluralista e secularizada.

Mas o desafio, aqui, é como elaborar uma bioética para os países do assim chamado Terceiro Mundo, levando-se em contas a realidade da vida dos pobres, que são a grande maioria, bem como o contexto a partir do qual ela se estrutura. Não se podem desconsiderar as necessidades básicas que estruturam a vida humana, tais como alimentação, saúde, habitação, trabalho.

\section{ATUALIDADE DA BIOÉTICA}

As novas descobertas tecnológicas mudaram profundamente a "face da terra" e a "face do homem" que vive na terra. Mudou a maneira de viver e de relacionar-se das pessoas; e mudou a vida mesma das pessoas. A tecnologia nos acompanha desde o nascimento até a morte.

As novas tecnologias mexem com a vida humana; possibilitam uma maior regulação da natalidade e conseguem, muitas vezes, vencer a esterilidade com técnicas que nem se sonhavam poucas décadas atrás: a inseminação artificial, o "bebê de proveta" etc.

No campo da saúde, as novas tecnologias possibilitam a cura de muitas doenças, a diálise, os transplantes (rins, fígado, coração). O PGH (Projeto Genoma Humano) identificou e mapeou os genes presentes na longa molécula do DNA. Todo este desenvolvimento tecnológico levantou sérias questões éticas.

A ética se baseia, essencialmente, no respeito da pessoa humana. Essas tecnologias respeitam sempre a pessoa humana? Não existe, por acaso, o risco de reduzir a pessoa a um objeto de manipulação?

São perguntas que interessam a todas as pessoas.

É preciso dialogar, numa atitude interdisciplinar, com o seguinte objetivo: colocar o progresso biomédico e tecnológico a serviço da vida humana e de toda a convivência social, e não contra.

A Bioética, assunto tradicionalmente reservado aos estudiosos de filosofia e aos mestres religiosos, na atualidade, passou a ser discutido pelos cidadãos comuns. Por exemplo debate-se sobre a eticidade dos modos de limitação da natalidade, eutanásia, pena de morte, 
homossexualismo; discute-se sobre a ética na política, na economia, na administração pública, na ecologia, na ciência e tecnologia.

Isso é explicado pelas mudanças estruturais ocorridas particularmente no século XX, que geraram novos comportamentos humanos.

Em primeiro lugar, o processo de industrialização, iniciado no século XIX, radicalizouse e expandiu-se vertiginosamente: a humanidade trocou literalmente o arado pela máquina, a vida no campo pela urbanização, com o consequente abandono de hábitos e tradições do mundo agrícola.

Entre os avanços da tecnologia, ocupam lugar de destaque a biologia e a medicina que alteraram profundamente o ciclo da duração de vida humana: o nascer, o viver e o morrer caem sob o controle da ciência, derrubando tradições e convicções que atribuíam a forças arcanas ou divinas, muitas manifestações de nosso corpo.

Entre as mudanças estruturais, nos últimos anos, a convivência da ciência com a técnica, deixando para trás a fase de industrialização, abriu a era da informática. Os braços que construíram e movimentaram as máquinas da era industrial foram substituídos, na pósmodernidade, pelos cérebros pensantes e criativos encarregados de pensar e inventar novas estratégias tecnocientíficas. Numa palavra, a velocidade das informações e a criatividade são, hoje, o segredo do sucesso do mundo tecnocientífico.

\subsection{Microética e macroética}

A reflexão ética acompanhou com dificuldade as transformações das estruturas organizacionais do mundo e das consequentes formas ou estilos de vida da humanidade. Além disso, as mudanças estruturais ocorridas na sociedade, no campo da ética provocaram a passagem da microética para a macroética.

É sabido que a ética grega, medieval e moderna, até meados do século XX, ocupou-se, com ênfase prioritária e, às vezes exclusiva, da ação individual; a ética sempre cuidou que a ação, que começa e termina no sujeito, seja realizada com liberdade, consciência e decisão pessoal.

Hoje vivemos a experiência da prioridade do sujeito-social devido às transformações supracitadas. Aqui, o sujeito da ação moral não é o indivíduo, mas o grupo, a associação, a comunidade política. Numa greve, por exemplo, não há uma pessoa responsável do movimento, mas uma entidade, um grupo organizado e publicamente identificado. A mesma reflexão vale para o ato da eleição, ação única feita por muitos, milhares e milhões de votantes. Portanto, na visão macroética inscrevem-se as atividades feitas em grupos econômicos, tecnocientíficos, sindicais, políticos e religiosos.

\section{OPERACIONALIZAÇÃO DO CONCEITO BIOÉTICA}

Os estudos desenvolvidos acerca da evolução da Bioética regional apontam que ela, como disciplina, não foi assimilada exatamente, assim, como foi concebida originariamente nos Estados Unidos. Eis que a Bioética percebida essencialmente como made in USA, envolvia uma abordagem da medicina e da saúde de estilo norte-americano. Contudo, o processo de assimilação da Bioética por parte dos países Latino-americanos deu-se, a partir dos anos 1980, com a restauração da democracia e a introdução de tecnologias médicas novas tais como o cuidado em fases críticas, os transplantes e a reprodução assistida etc. Já, nos anos 1990, a Bioética latino-americana recriou-se a si mesma, incorporando as tradições intelectuais e morais próprias da região. Em consequência, uma identidade ética regional distintiva tornou-se o modelo bioético latino-americano. Revelou-se, assim uma característica importante da Bioética latinoamericana: seu interesse global. A Bioética passou a ser enciclopédica por definição, etimologicamente "ética da Vida". Afirma-se, assim, que, por conta desse conceito global os 
princípios de solidariedade e de justiça desempenham o papel central na Bioética latinoamericana diferentemente do papel preponderante que a autonomia tem na Bioética norteamericana (MAINETTI, 2007, p. 38-40)

Contudo, para entender o lugar que ocupa a Bioética no contexto sociocultural latinoamericano e, assim, pode caracterizar e designar seus fundamentos teórico-metodológicos, principiológicos e valorativos, faz-se necessário identificar a realidade "biomoral" sobre a qual a Bioética latino-americana se erige e que, certamente, pode ser objeto de investigação jusfilosófica, servindo de referência para a resolução dos problemas (dilemas) bioéticos regionais.

Assim, como se afirma que há um ethos norte-americano que define o modo de pensar dos estadunidenses acerca da moralidade e que há dado lugar às transformações e ao desenvolvimento da medicina de Estados Unidos numa disciplina e um discurso chamado de Bioética, pode-se também afirmar que há um ethos latino-americano que define o modo característico em que América Latina interpreta sua história, seu mundo social, com base em normas e valores comuns. Esse ethos não deve ser considerado como uma coletânea de regras, princípios e valores invocados, mas como o modelo em que essas regras, princípios e valores se constituem (TEALDI, 2008, p. 18)

Em síntese: a identidade latino-americana, como lugar comum para a Bioética é, precisamente, a realidade "biomoral", isto é, aquela dimensão sociocultural e moral que pode ser estudada, definida e caracterizada (LÉRTORA, 2008, p. 5). Essa identidade é definida pelo conjunto de estruturas, a saber, costumes, valores e normas morais que têm como traços comuns:

a) a representação simbólico-conceitual, devido à proximidade das línguas espanhol e português, que se sabem derivadas do latim (proximidade da linguagem) e que se constitui como um recurso importante para a interpretação, culturalmente transmitido de geração para geração;

b) a tradição jurídica e cultural (que definem a proximidade jurídico-normativa) que "advém de uma tradição latina e mediterrânea de que derivam características altamente específicas" (GARCIA, 2007, p. 17) e;

c) a forte influência da religião cristã, que define a uniformidade axiológica fundada em doutrinas e valores cristãos e o possível reconhecimento dos princípios que orientam a conduta humana.

Diz-se, assim, da existência de um conjunto de valores compartilhados que define a identidade da região. Esta condição foi reconhecida recentemente pela UNESCO, na Convenção sobre Diversidade Cultural: Valores culturais e identidade comunitária.

Todavia, considera-se que, devido à grande diversidade de aspectos que configuram a cultura em todas suas manifestações, torna-se difícil delinear um mapa dos valores culturais, fundamentalmente porque alguns setores, que podem ser incluídos na cultura em sentido amplo, têm autonomia axiológica, tais como a beleza, o conhecimento e a religião. Por esse motivo, talvez a solução seja considerar os valores culturais mais em relação com a comunidade. Neste sentido, os valores culturais constituiriam um patrimônio comunitário vinculado à identidade das sociedades. Assim, por ter um valor patrimonial, esse conjunto de valores deve ser protegido (tutelado) pelos representantes da comunidade. Todavia, no seio das sociedades latinoamericanas existem valores fundamentais, aqueles que a maioria considera como condição necessária para a existência plena da mesma, por exemplo, sua estrutura societária (família, instituições, comunidades etc.). A conservação desses valores fortalece a comunidade, mas a perda axiológica a torna vulnerável. Outros valores são importantes como complemento dos anteriores, mas não necessariamente condição de existência ou de conservação comunitária, por exemplo, a liberdade, a autodeterminação, a independência. Observa-se que uma perda absoluta da liberdade e da autonomia, de fato, acaba com a sociedade como unidade diferenciada de outras com as quais, eventualmente, se mistura. Em suma, há valores culturais que podem ser considerados valores vitais (fundamentais), isto é, valores de todos. Assim, por exemplo, a vida, a 
qualidade de vida, a dignidade etc., que pressupõem a vida biológica (LÉRTORA, 2008, p. 38). Nesse sentido, quem atenta contra esses valores, atenta, também, contra a convivência comunitária.

Os rasgos anteriormente definidos constituem os indicadores que justificam o que, também, propomos chamar de "latinidade inclusiva": comunidade regional definida e constituída pelo bloco de países marcados, fundamentalmente, pela tradição histórica, cultural, jurídica, moral e religiosa que começou a ser edificada na região, durante o processo de colonização e domínio imposto pelos países da Península Ibérica (Espanha e Portugal). Esses rasgos introduzidos e definidos a partir da colonização hispano-portuguesa foram, posteriormente, se perpetuando em cada país, primeiro, pelo anseio de independência das colônias, não só das suas metrópoles originárias e, segundo, pela rejeição à dependência aos Estados Unidos. Tudo isso, reafirma as condições favoráveis para a idealização de um novo modelo para a codificação e a edificação da Bioética latino-americana.

Destarte, os conceitos "realidade biomoral" e "identidade" abrem um espaço para a análise e o debate dos problemas bioéticos comuns da região, com o intuito de superar o ceticismo bioético e concretizar a nossa proposta de unificação normativa (codificação) e de edificação da consciência.

A dúvida acerca da existência de uma identidade latino-americana se observa no argumento fundado no conhecido extermínio da população originária indígena, oriunda das conquistas produzidas entre 1492 a 1557, que culminou na destruição das três grandes civilizações (Asteca, Maia e Inca), representativas de uma população indígena estimada em sessenta milhões até o descobrimento da América, que foi reduzida a dez milhões, aproximadamente. A não identidade se agravaria pela contradição gerada pelo processo de mestiçagem produzido entre 1557-1804 que originara o conflito étnico, religioso e sociocultural até hoje existente entre brancos, índios e negros. Contudo, um novo século, marcado pela formação dos estados nacionais (1804-1902), começaria com a independência de Haiti em 1804, da Venezuela em 1811 até a independência de Cuba em 1902 (mesmo que este último já tinha deixado de ser território espanhol em 1898), caracterizado por acentuadas disputas entre os Estados Unidos e os países europeus pelo controle político e econômico da região. Após quatro séculos, especificamente, no século XIX afirma-se a recuperação da cifra de sessenta milhões da população estimada no início do descobrimento e, somente no século XX, se falaria de um sentimento latino-americano que estimularia a procura pela identidade regional. Surgiria, assim, um novo ideário político arquitetado pelo processo de criação de constituições liberais, com base na Declaração de Independência dos Estados Unidos em 1776: a abolição da escravatura, a liberdade de expressão, o livre comércio, a propriedade privada e a liberdade de pensamento e de crenças religiosas. Vê-se, assim, o surgimento de uma base axiológica para a Bioética regional (TEALDI, 2008)

Em suma, o problema da identidade da América Latina tem sido abordado a partir de variados enfoques, a saber, metafísico, psicológicos e até literários (LÉRTORA, 2008, p. 5). Porém, a abordagem jurídica e moral é, sem dúvidas, a que mais nos interessa.

\section{CONCLUSÃO}

Como resultado do presente estudo, alerta-se acerca das consequências negativas do uso inconsequente dos avanços científicos e tecnológicos. Nesse sentido, sugere-se indagar até que ponto a autonomia (liberdades) coloca em risco a convivência.

Considera-se que a ingerência no patrimônio genético pode gerar um desequilíbrio do ecossistema, fundamentalmente no campo microbiológico, e assim afetar a saúde das atuais e futuras gerações. Logo, o problema fundamental da Bioética moderna é evitar a autodestruição. 
A Bioética latino-americana e, por extensão, as discussões que têm como centro os seus problemas hão de estar balizadas pelo humanismo e o funcionalismo das ciências, fundamentalmente, da Medicina e do Direito. É, pois, por meio de uma abordagem humanista que deixamos de lado o fatalismo para privilegiar a convivência.

Problemas tais como o consentimento informado, a definição do início e do fim da Vida, o transplante de órgãos, o aborto, as experiências com seres humanos e animais, a eutanásia, a reprodução medicamente assistida, a clonagem humana e de animais para fins terapêuticos etc. estão em estreita correlação e conflito com o direito à Vida, à liberdade, ao bem-estar e à felicidade de cada ser humano.

Alguns desses problemas ${ }^{1}$, no contexto moderno, deixaram de ser nacionais para se transformarem em problemas de interesse geral/global, por estarem vinculados aos direitos humanos e fundamentais, cuja negação incide negativamente sobre a subsistência da Vida e do Planeta.

Certamente, nas sociedades modernas princípios e valores muitas vezes se colocam em conflito ou são usados em detrimento da convivência, sob o pretexto de que todo ser humano é um ser livre e merece o reconhecimento da sua autonomia. Decerto que, a autonomia (as liberdades) sem limite, também pode vir a ferir a convivência. A preferência e o predomínio do citado princípio geram uma visão estreita e egoísta de quem se usa da tecnologia e das pesquisas para lucrar e satisfazer interesses individuais/empresariais, sem se levar em conta os aspectos sociais: a saúde, a segurança, a inclusão, a produção e acesso a medicamentos, a melhoria de tratamentos e serviços médicos etc. Tal preferência pode e deve ser qualificada irracional por constituir evidente violação dos Direitos Humanos.

Considera-se, assim, a codificação, o ensino e a edificação dos valores bioéticos uma condição para o desenvolvimento, o progresso e o bem-estar de todos os latino-americanos e, por extensão, da humanidade. De fato, o progresso alcançado nos últimos 100 anos, no campo das ciências e da tecnologia biológicas, de nada vale se é utilizado em detrimento do próprio homem.

Não há conflito entre o desenvolvimento científico e a humanidade quando esse desenvolvimento é considerado parte dos direitos humanos, isto é, como um direito do homem que deve ser preservado pela Ética, pela Educação e pelo Direito.

Não há como negar a ciência; ora, devido aos riscos que as liberdades sem limites acarretam, deve-se pensar em como fazer uma ciência eticamente livre, mas também responsável.

Tratemos, pois, de reconhecer que seres humanos são seres sociais e que a sociedade se expressa como um sistema equitativo de cooperação social dos seus membros e representantes. A tecnocracia que hodiernamente domina o homem deve ser colocada a serviço do homem. A Bioética e o Biodireito, assim, devem ser entendidos como microssistemas que combinam "ciência", "consciência" e "convivência": a solidariedade e a cooperação.

Conclui-se que a convivência social se sabe condicionada ao respeito, à solidariedade, à responsabilidade e à cooperação e que tais são os critérios e princípios supremos da Bioética latino-americana e mundial que devemos promover se realmente almejamos a proteção do meio ambiente, da biosfera e da biodiversidade e das gerações futuras.

\footnotetext{
${ }^{1}$ Tais são os casos da desaparição de espécies vegetal e animal, o aquecimento global que é causa das catástrofes, da contaminação ambiental a escassez de água potável, as possíveis consequências ou efeitos na saúde causada por organismos geneticamente modificados etc.
} 


\section{REFERÊNCIAS BIBLIOGRÁFICAS}

ARPINI, Adriana. Pluralismo. In: TEALDI, Juan Carlos. Diccionario latinoamericano de Bioética. Bogotá: UNESCO - Red Latinoamericana y del Caribe de Bioética: Universidad Nacional de Colombia, 2008. p. 36.

ALMEIDA, Aline Mignon de. Bioética e Biodireito. Rio de Janeiro: Lumen Juris, 2004.

BEAUCHAMP, T.; CHILDRESS, J. F. Principles of biomedical ethics. 4. ed. New York-Oxford: Oxford University Press, 2001.

CORREIA, Francisco de Assis. Alguns Desafios atuais da Bioética. In: PESSINI, Léo; BARCHIFONTAINE, Christian de Paul de. (Orgs.). Fundamentos da Bioética. São Paulo: Paulus, 1996. p. 30-50.

DELlA CUNHA, Djason B. Biodireito: o novo Direito face à Bioética. Revista da Esmape, Recife, v. 6, n. 13, p. 93-109, jan./jun. 2001.

DINIZ, Maria Helena. O Estado atual do Biodireito. 9. ed. São Paulo: Saraiva, 2014.

GARCIA, Diego. O contexto histórico da Bioética hispano-americana. In: PESSINI, Leocir. Bioética na Ibero-América. São Paulo: Centro Universitário São Camilo: Loyola, 2007.

GONZÁLEZ, Juliana. Tolerancia. In: TEALDI, Juan Carlos. Diccionario latinoamericano de Bioética. Bogotá: UNESCO - Red Latinoamericana y del Caribe de Bioética: Universidad Nacional de Colombia, 2008. p. 118.

HOSS, Geni Maria. Fritz Jahr e o Imperativo Bioético Debate sobre o início da Bioética na Alemanha e sua importância em nível internacional. Bioethikós, São Paulo, n. 7, v. 1, p. 84-86, 2013. Disponível em: 〈http://www.saocamilo-sp.br/pdf/bioethikos/99/a10.pdf>. Acesso em: 15 abr. 2015.

LÉRTORA, Celina. Filosofía latinoamericana. In: TEALDI, Juan Carlos. Diccionario latinoamericano de Bioética. Bogotá: UNESCO - Red Latinoamericana y del Caribe de Bioética: Universidad Nacional de Colombia, 2008. p. 5.

MAINETTI, José Alberto; PEREZ, Marta Lucia. Os discursos da Bioética na América Latina e referências de Bioética na Argentina. In: PESSINI, Leocir. Bioética na Ibero-América. São Paulo: Centro Universitário São Camilo: Loyola, 2007. p. 35.

NEIRA, Hernán. América Latina y Bioética. In: TEALDI, Juan Carlos. Diccionario latinoamericano de Bioética. Bogotá: UNESCO - Red Latinoamericana y del Caribe de Bioética: Universidad Nacional de Colombia, 2008. p. 156-159.

PEGORARO, O. Ética na Contemporaneidade. In: PESSINI, Léo; BARCHIFONTAINE, Christian de Paul de. (Orgs.). Fundamentos da Bioética. São Paulo: Paulus, 1996. p. 75-88.

PESSINI, Léo; BARCHIFONTAINE, Christian de Paul de. Problemas atuais de Bioética. 8. ed. rev. e ampl. São Paulo: Loyola, 2007. 
RAMPAZZO, Lino. Ciência e Tecnologia, Bioética e Biodireito. In: NUNES JÚNIOR, Flávio Martins Alves; NASCIMENTO, Grasiele Augusta Ferreira (Orgs.). O Direito e a Ética na sociedade contemporânea. Campinas; Alínea, 2006. p. 85-96. Cap. 5.

. O personalismo de Mounier: uma inspiração para a Bioética? Revista Bioethikos, v. 8, p. 330-341, 2014. Disponível em: 〈http://www.saocamilo-sp.br/pdf/bioethikos/155564/A07.pdf〉. Acesso em: 20 ago. 2016.

RAMPAZZO, Lino; JIMÉNEZ SERRANO, Pablo; MOTTA, Ivan Martins Motta (Orgs.). Direitos Humanos e Bioética. Lorena: Unisal, 2014. Disponível em: <http://www.lo.unisal.br/direito/semidi/publicacoes.aspx?livro=DHBIO>. Acesso em: 20 ago. 2016.

SANTOS, Maria Celeste Cordeiro Leite. (Org.). Biodireito: Ciência da vida, os novos desafios. São Paulo: Revista dos Tribunais, 2001.

SERRANO, Pablo Jiménez. Fundamentos da Bioética e do Biodireito. Campinas: Alínea, 2013. . Curso de Filosofia Jurídica. Rio de Janeiro: Jurismestre, 2015.

Fundamentos de filosofia moral: conceitos básicos da filosofia aplicada. [livro eletrônico] / Pablo Jiménez Serrano. - Rio de Janeiro: Jurismestre, 2015.

SIQUEIRA, José Eduardo de. Educación en Bioética. In: TEALDI, Juan Carlos. Diccionario latinoamericano de Bioética. Bogotá: UNESCO - Red Latinoamericana y del Caribe de Bioética: Universidad Nacional de Colombia, 2008. p. 270-273.

SGREGGIA, Elio. Manual de Bioética: I - Fundamentos e Ética Biomédica. Tradução de Orlando Soares Moreira. 2. ed. São Paulo: Loyola, 2002.

UNESCO. A Declaração Universal sobre o Genoma Humano e os Direitos Humanos. 16 nov. 1999. Disponível em: <http://unesdoc.unesco.org/images/0012/001229/122990por.pdf>. Acesso em: 15 set. 2014.

TEALDI, Juan Carlos. Diccionario latinoamericano de Bioética. Bogotá: UNESCO - Red Latinoamericana y del Caribe de Bioética: Universidad Nacional de Colombia, 2008.

UNESCO. Declaração Universal sobre o Genoma Humano e os Direitos Humanos (artigos 10 e 11). Disponível em: http://unesdoc.unesco.org/images/0012/001229/122990por.pdf. Acesso em: $15,09,2014$.

UNESCO. Declaração Universal sobre Bioética e Direitos Humanos (artigos 6º. Disponível em: http://unesdoc.unesco.org/images/0014/001461/146180por.pdf. Acesso em: 15, 09, 2014. (Grifo nosso)

VÁZQUEZ, Rodolfo. Ponderación de principios éticos. In: TEALDI, Juan Carlos. Diccionario latinoamericano de Bioética. Bogotá: UNESCO - Red Latinoamericana y del Caribe de Bioética: Universidad Nacional de Colombia, 2008. p. 171. 